\title{
Volver a la esencia del cine. Hacia una revisión de sus formas expresivas
}

\author{
Mercedes Miguel BorRÁs \\ Universidad de Valladolid \\ mermiborras@gmail.com
}

\begin{abstract}
Resumen
La vertiginosa evolución de los medios audiovisuales está pidiendo a gritos un replanteamiento de las formas expresivas -que no viajan tan rápido como la técnica- con las que la realidad se inscribe en la representación. ¿Despojar al cine del artificio puede provocar un mayor acercamiento a su pureza? Exploramos en el concepto de Realismo; estudiamos a los primeros teóricos interesados en buscar los parámetros que confieren al cine su esencia. Esto nos permite entender y atender su sustancia expresiva para acercarnos a la poética presente en la propia naturaleza del discurso cinematográfico.
\end{abstract}

Palabras clave: Esencia del cine - Escrituras realistas - Cine y realidad - Naturaleza poética del cine.

\section{Back to the essence of cinema. To a reconsideration of its expressive forms}

\begin{abstract}
The rapid change in the media is clamoring for a rethinking of the expressive forms -which do not travel as fast as technically- with which reality is part of the representation. To deprive the film of artifice, can cause a greater approach to its purity?

We explore the concept of Realism; we study the first theorics interested in finding the parameters that give the cinema its essence. This allows us to understand and address its expressive substance to near us to the poetic which is inside in the own nature of the cinematographic discourse
\end{abstract}

Key words: : Essence of cinema - Scriptures realistic - Film and reality - Nature poetic cinema.

\section{Referencia normalizada:}

Miguel Borrás, M. (2013) Volver a la esencia del cine. Hacia una revisión de sus formas expresivas. Historia y Comunicación Social. Vol. 18. № Especial Octubre. Págs. 33-48.

Sumario: 1. Introducción. 1.1. Metodología. 2. Inscribir la realidad en la representación. 2.1. De qué hablamos cuando hablamos de realismo. 2.2. La esencia del cine. 2.2.1. Poética del cine. 2.2.2. Libertad creadora. 3. Hacia un replanteamiento de la esencia del cine. 3.1. La forma del film es su materia. 3.2. Una ética de la representación. 3.3. Buscar la verdad de las cosas. 3.3.1. Roberto Rossellini. 4. Ipotesi Cinema. 4.1. Principios para una scuola-non scuola. 4.1.1 Osolemio: autoritratto italiano. 5. Coda conclusiva: la esencia del cine según Mario Brenta. 6. Bibliografía. 7. Apéndice. Breve curriculum vitae.

\section{Introducción}

En 1948, en plena eclosión del Neorrealismo, el director y crítico francés Alexander Astruc desvelaba interesantes aspectos sobre las posibilidades expresivas del cine, cuando en su célebre artículo El nacimiento de una nueva vanguardia: la caméra-stylo, señalaba: 
El cine está a punto de encontrar una forma con la que se convertirá en un lenguaje tan riguroso que el pensamiento podrá inscribirse directamente sobre la película... La cámara en el bolsillo derecho del pantalón, la grabación del sonido y la imagen en una banda de meandros... Un cine de confesión, de ensayo, de revelación, de mensaje, de psicoanálisis, obsesión, una máquina de lectura para palabras e imágenes de nuestro paisaje personal ${ }^{1}$.

A la luz de los universos virtuales en los que se enmarcan los relatos audiovisuales en la actualidad, capaces de construir realidades en ausencia del referente, las premoniciones de Astruc tendrían ciertos visos de verdad. Pero el hecho es bien diferente, la técnica está por encima de las ideas que aún no han encontrado el acomodo necesario en el que representarlas (construirlas).

Los medios audiovisuales han evolucionado de forma vertiginosa y están pidiendo a gritos un replanteamiento de las formas expresivas con las que la realidad se inscribe en la representación. El discurso sobre el realismo necesita una renovación para poder legitimarse.

Cuando en 1959 Gilbert Cohen-Séat, fundador del Instituto de Filmología de París, daba carta de naturaleza a la iconosfera para definir ese nuevo ecosistema cultural creado con la instauración definitiva de los medios audiovisuales en la civilización, no sospechaba el efecto de ocultamiento que con los años iba a producir su acumulación. Este ecosistema ha ido desplazando la expresión icónica hacia sus usos como mercancía de consumo más que como medio de conocimiento científico; creando "un paisaje caracterizado por la opulencia mediática cuyas imágenes pueden llegar a convertirse en una falsa realidad... un contraefecto que no se había previsto, a saber, que el exceso de imágenes las hace invisibles" (Gubern, 1996: 123). Pero imagen siempre implica representación, es un signo (y por definición sustituye el objeto real por el representado), expresión de una determinada ideología. "Ciego vidente" denomina Santos Zunzunegui "al espectador que acumula imágenes asimilándolas como realidad sin preguntarse qué tipo de mensaje está recibiendo” (1998: 24)

El cine es el más secreto de los lenguajes artísticos, el menos comprendido también. Producto y nada más que producto (según la dictadura del mercado, más implacable que nunca, hasta el punto que ha conseguido la enajenación de la noción de autor), al cine hoy el poder establecido sólo le ofrece un destino único: el industrial. Es por ello que, en esta encrucijada, quizás no le quede otra alternativa que replegarse sobre sí mismo para, asumiendo su soledad, afirmarse en su dignidad: la de ser el último de los lenguajes artísticos inventados por el hombre. (Erice, 1997: 26).

Este sentimiento expresado por el cineasta Víctor Erice ya estaba presente en el Manifiesto de las Siete Artes, escrito por Ricciotto Canudo en 1911 (aunque publicado en 1914):

Muchos y nefastos tenderos del cine han creído poderse apropiar del término "Séptimo Arte" que da prestigio a su industria y a su comercio, no han aceptado

1 "Nacimiento de una nueva vanguardia: la caméra-stylo" fue publicado en L'Écran Français (nº 144) el 30 de marzo de 1948. 
empero la responsabilidad impuesta por la palabra "arte". Su industria sigue siendo la misma, más o menos bien organizada desde el punto de vista técnico; su comercio se mantiene floreciente o en decadencia, según los altibajos de la emotividad universal. Su "arte", salvo algún raro ejemplo en el que el cineasta es capaz de exigir e imponer su propia voluntad, sigue siendo prácticamente el mismo que inspiraba a Xavier de Montépin ${ }^{2}$.... Necesitamos al Cine para crear el arte total al que, desde siempre, han tendido todas las artes".

Ideas latentes en intelectuales y artistas que han recorrido el cine desde su nacimiento en ese persistente intento por salvaguardarlo de las garras de la banalización del arte. Podemos pensar que la calurosa acogida en los últimos años de The Artist (Michel Hazanavicius, 2011) y Blancanieves (Pablo Berger, 2012) films inscritos en el cine silente, se encuentre en la misma senda por la que caminaba Chaplin cuando se negó a utilizar el sonido hasta más de diez años después de su aparición, al considerar que despojaba al cine de su fuerza expresiva ${ }^{3}$.

En De Caligari a Hitler (1947), Siegfried Kracauer planteaba un problema crucial para entender lo que estamos diciendo: dado que el cine permite acceder al conocimiento del mundo ¿cómo le afecta la expresividad? El problema, decía André Bazin es que es índice (señala) y es icono (simboliza); su esencia es ser huella, certifica la realidad, da carta de naturaleza al pasado; pero la realidad en la que se sustenta el mundo no es empírica, la cámara esta condicionada por la intencionalidad del sujeto (1959).

\subsection{Metodología}

La reflexión sobre estos temas nos lleva a plantearnos si el despojar al cine del artificio (artefacto) puede provocar un mayor acercamiento a la pureza de las formas expresivas, y nos conduce hacia dos cuestiones cruciales a resolver: cómo se inscribe la realidad en el cine y cuál es la sustancia expresiva de la que se nutre.

Exploramos en el concepto de Realismo en el arte y, consecuentemente, en el cine. Tomando como referencia la pregunta formulada por André Bazin ¿Qué es el cine?, dirigimos nuestra atención hacia los primeros teóricos para leer con otra mirada -la de esos ojos saturados por imágenes cargados con tanta memoria impostada- a Canudo, Balázs y Kracauer.

Partimos, siguiendo las ideas de Ángel Quintana (que ha dedicado numerosos trabajos al estudio de las escrituras realistas), de una reformulación del realismo genético, "un discurso epistemológico abierto al conocimiento del mundo, que habla de la relación de los individuos y las cosas" (Quintana, 2003:43).

La poética presente en el cine de Roberto Rossellini nos permite adentrarnos en el seno de Ipotesi Cinema, una escuela de cine que investiga en el lenguaje audiovisual

2 Autor de folletines y dramas populares como La Porteuse de pain, publicado entre 1884 y 1889, ha sido adaptado al teatro, cine y televisión.

3 Su primera película totalmente sonora fue El gran dictador (The Great Dictator, 1940). 
buscando la esencia del cine, o de la realidad, que para estos cineastas forma parte de una misma idea.

Diferentes aproximaciones metodológicas nos han acercado a nuestro estudio: rastreamos en las huellas del realismo a través de las teorías de Siegfrid Kracauer, continuando con Marc Ferro y más recientemente los estudios de Ángel Quintana. El análisis de los films, está apoyado en la Teoría del Texto (Jesús González Requena) y, por supuesto, la Semiología en cuanto al estudio y significación de los signos. Las investigaciones de los Estructuralistas, desde Roman Jakobson a Roland Barthes, serán el punto de partida y de llegada de nuestro trabajo.

\section{Inscribir la realidad en la representación}

"Una novela es como un espejo colocado a lo largo del camino". Estas palabras, pronunciadas por Stendhal en la segunda mitad del siglo XIX, destapaban la caja de Pandora, todavía abierta, en torno al Realismo: la forma en la que dotar de significación a ese camino.

\section{1. ¿De qué hablamos cuando hablamos de realismo?}

Qué es la realidad y cómo se inscribe en la representación ha sido uno de los grandes retos del Realismo.

Los estudios sobre el Realismo en el arte nos conducen hacia Erich Auerbach para quien la realidad está condicionada por el modelo del mundo del que parte cada cultura. Un realismo, señala el filólogo y crítico literario, que se preocupa por la relación que el artista establece con su entorno, al que observa e intenta reproducir fielmente, que interroga al mundo e intenta saber cómo funciona (Mimesis: la representación de la realidad en la literatura occidental, 1946). Pero también, aunque desde planteamientos diferentes, nos acercan a Ernst Gombrich: la representación, señala el teórico del arte, supone que el artista ordene y seleccione la realidad en un universo simbólico. Para Gombrich el Realismo resulta de convenciones y reglas del lenguaje que pueden ser precisadas. Igual que la pintura introduce color, como medio de expresión, la obra crea la realidad desconectada del mundo (Arte e ilusión, 1960). Es lo que los Formalistas Rusos, y teóricos y artistas del Círculo Lingüístico de Praga denominan la literalidad: lo que separa al arte de la realidad, formando parte del debate abierto en los años veinte del pasado siglo entre el dramaturgo Bertolt Bretch y el filósofo y crítico literario Georg Lukács. Ambos están influidos por Lenin y comparten el espíritu crítico y la voluntad de transformación de la sociedad, pero un abismo separa sus concepciones estéticas:

Para Lukács el arte ofrece una visión dialéctica, completa de la realidad y debe revelar la construcción del mundo social, resultado de la interacción entre los hombres. Busca un modelo estético en el pasado defendiendo la novela clásica 
realista y rechazando a los modernistas, incluyendo el cine de Sergei Eisenstein (de quien hablaremos más adelante). Para este teórico marxista el realismo es una forma artística que permite reproducir la esencia histórica objetiva. El arte debe ser valorado por su mayor o menor reflejo de la realidad. En franca oposición Bretch considera el arte más que un reflejo; debe criticar y negar la realidad existente para ir más allá del reconocimiento cotidiano. Aboga por un realismo crítico que conjuga las corrientes vanguardistas con la estética realista defendida por Lukács. El arte puede ser una herramienta de reproducción o de transformación; la obra que sólo se ciña a aspectos ideológicos niega al arte su capacidad para mostrar la complejidad de los fenómenos humanos. Una verdad concreta, lejos de ambigüedades que sólo el arte es capaz de restablecer (Bokser, 2011).

Defensores de la mímesis y el distanciamiento estético como formas de acercamiento a la realidad, respectivamente, Lukács y Bretch ponían en evidencia una polémica latente en intelectuales y artistas, de la que el cine, este nuevo lenguaje que se descubría con infinitas posibilidades expresivas, era uno de los principales focos de atención.

\subsection{La esencia del cine}

Con la llegada del siglo XX la crítica y el estudio del cine prende con fuerza en el seno de las vanguardias que estigmatizaban la realidad como sustrato del nuevo arte 4 . Fue en París, que se había convertido en un hervidero en el que se daban cita intelectuales y artistas (la libertad creadora de Marcel Proust, los collages de Max Ernst, el psicoanálisis...), donde redactó el joven Canudo su célebre Manifiesto. Planteaba el teórico que el arte surge de ese deseo de los hombres por plasmar una experiencia estética fuera de la vida normal; el cine las sintetiza, al fusionar el ritmo espacial (arquitectura, pintura, y escultura) y el temporal (música, danza y poesía). Pero no debemos llevarnos a engaño, aunque los primeros estudios sobre el cine tenían un carácter formalista (Sergei M. Eisenstein, Hugo Münsterberg, Béla Balázs, Rudolf Arnheim), también en esos años Siegfried Kracauer investigaba sobre la inscripción de la realidad en el cine ${ }^{5}$, y Dziga Vertov, uno de los grandes pilares del documental (cuya vertiente estética, al igual que Eisenstein procedía de las vanguardias) rechazaba la manipulación en el cine. Vertov reivindicaba el uso de la cámara como un ojo fílmico (más perfecto que el ojo humano), para explorar el caos de los fenómenos visuales que llenan el universo.

4 Ejemplo de este espíritu vanguardista del que hablamos sería el ensayo Las estéticas, las trabas, la cinegrafía integral (1927) en el que la cineasta Germaine Dulac plantea que la naturaleza artística del cine no está en fotografiar la realidad; el movimiento es "la música de los ojos".... la esencia del cine lleva consigo la eternidad pues procede de la esencia del universo.

5 Kracauer publicó su primer escrito sobre cine en 1920, El filme como educador, escrito en el Frankfurter Zeitung, periódico en el que colaboraba y cuyos artículos están reunidos en Ornament der Masse (1927). Años después publicaría: De Caligari y Hitler. Una historia psicológica del cine alemán (1947) y Teoría del cine: la redención de la realidad fisica (1960). 


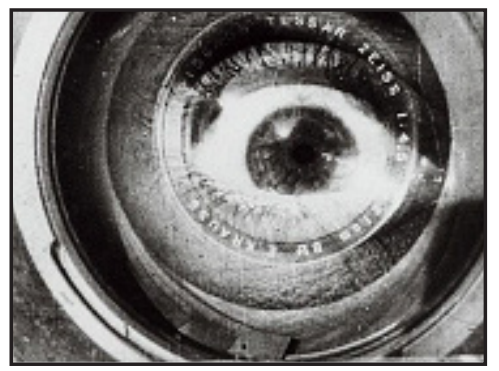

Sus ideas fueron reflejadas en una serie de Manifiestos escritos junto al grupo Kino-Pravda -también conocido como Kino-glaz (cine-ojo)- que serían objeto de una polémica con Eisenstein por sus divergencias entre realidad y ficción. "Yo no hago cine ojo, hago cine puñetazo.... El registro de la vida no es cinemático...." decía el cineasta Formalista. Debate abierto que proseguiría con los teóricos Realistas (que hacían su entrada con la llegada del sonoro), como Guido Aristarco y André Bazin. Para Bazin, defensor a ultranza del Realismo, el cine es el arte de lo real porque registra la espacialidad de los objetos. Idea que se opone frontalmente a las Teorías del montaje esgrimidas por los Formalistas.

Pero más allá de sus disputas teóricas, lo que les une a todos es un mismo deseo por dotar al cine del lugar que le corresponde como arte. Tanto para Vertov como para Eisenstein, el lenguaje del cine era una herramienta que les permitía mostrar la realidad de su tiempo.

Balázs y Kracauer, desde posiciones diferentes, conciliaban ambas teorías. En El hombre visible (1924), uno de los primeros libros en abordar el cine como lenguaje, Béla Balázs rechaza el esteticismo per se. El cine, decía el dramaturgo y teórico húngaro, no trabaja la realidad, sino el tema, y la forma debe de estar de acuerdo con ella. Algo que también comparte Siegfried Kracauer, para quien la vida es el principal vehículo de transmisión de pensamientos y emociones. El periodista y teórico alemán (cuyas ideas están vinculadas a grandes pensadores como Theodor Adorno y Walter Benjamin), señalaba que el cine puede tener aspectos ligados al Formalismo siempre que estén supeditados al contenido ${ }^{6}$.

\subsubsection{Poética del cine}

Más allá de la divergencia en la sustancia expresiva, lo que une a toda experiencia artística es la literalidad; germen del universo poético con el que el creador expresa sus ideas; una alteración profunda de las leyes que rigen nuestro universo cotidiano. El lenguaje poético opera un cambio esencial en las relaciones entre el significante y el significado. Un juego producido en las relaciones sintagmáticas y paradigmáticas que lo lleva a alejarse de su uso cotidiano, volviéndolo ambiguo convirtiéndolo en una lengua extraña (García Arance, 1983).

Es ese "exceso de material significante presente en el lenguaje" (Jakobson, 1963), que en el cine se crea mediante el espacio metafórico generado por el montaje ( $E l$

\footnotetext{
6 La preocupación de estos primeros teóricos por desvelar la esencia del cine, estaba dando entrada, a finales de los sesenta a su poderosa incursión dentro del conocimiento científico, a partir de la Gran sintagmática de Christian Metz (publicada en Problemas de significación en el cine, 1964-68), la semiología y los estudios postestructuralistas que abordaron el film como texto y, con ello, la formalización del discurso para establecer las reglas que permiten su articulación.
} 
acorazado Potemkin, Bronenosets Potyomkin, 1925), pero también con la profundidad de campo (Ciudadano Kane; Citizen Kane, O. Welles, 1940), los movimientos de cámara y personajes (Madame de..., M. Ophuls, 1953), el fuera de campo (Un ladrón en la alcoba, Trouble in Paradise, E. Lubitsch, 1932), o el empleo dramático del espacio escénico (Ladrón de bicicletas; Ladri di biciclette, 1948). Esta articulación de rasgos poéticos y lingüísticos confiere al texto artístico de una singularidad estructural que provoca asociaciones distintas de la neutralidad comunicativa (García Berrio, 1994) y evidencia que, más allá de las diferencias expresivas, los rasgos poéticos están inscritos en la propia naturaleza del cine (Miguel Borrás, 2006).

\subsubsection{Libertad creadora}

Las obras maestras del cine fueron poniendo en evidencia la insuficiencia de los planteamientos reductores. En la revisión que Aristarco hizo en 1960 sobre Historia de las teorías cinematográficas (1951), este defensor del Realismo (y uno de los grandes impulsores del Neorrealismo), señalaba que una obra se valora desde un criterio integrador e integrado en su contexto; desde ahí se entiende el cambio de los planteamientos estéticos en los que se produce.

Es la forma de abordar la realidad, alejada de todo artificio, lo que queremos rescatar del Realismo. Cercana a la poesía, como ocurre en el cine de Jean Vigo ${ }^{7}$; sesgada hacia el Naturalismo, cuyo ejemplo señero sería Jean Renoir ${ }^{8}$ o, unos años antes, Erich von Stroheim; pero también inmersa en la plasmación de un país que había quedado en ruinas, como ocurriera a los films surgidos en el seno del Neorrealismo italiano. Sus renovadas estructuras preludian las rupturas provocadas en los años sesenta con las Nuevas Olas y señalan hacia ese replanteamiento de la esencia del cine objeto de nuestro trabajo.

Impregnados de lo cotidiano o lo instantáneo, los cineastas de la Nouvelle vague daban entrada a este movimiento renovador, al romper con las ataduras de la industria para reivindicar el cine como lenguaje. Como los Neorrealistas, buscaban una mayor acercamiento a la realidad a través de las formas expresivas pero, si a éstos unía un mismo espíritu de denuncia social, la arbitrariedad temática fue una de las características que definían a los cineastas de la Nouvelle vague. El realismo se reducía en ocasiones a la descripción exterior de las cosas (Alain Resnais, Hiroshima mon amour, 1959) o El año pasado en Marienbad (L'année dernière à Marienbad, 1961); las rupturas narrativas de Godard en Banda aparte (Bande à part, 1964) o se acercaban

7 En su corta carrera (murió a los 26 años), siempre al margen de la industria, realizó tres films: el documental À propos de Nice (1929), en el que dejó patente su admiración por Vertov y Stroheim; Cero en conducta (Zéro de conduite, 1932), canto anarquista contra la institución académica (prohibido hasta 1946), y L'Atalante (1934), film a caballo entre la poesía surrealista y el naturalismo.

8 Renoir dejó patente su humanismo en filmes como La gran ilusión (La grande ilusion, 1937) y La regla del juego (La règle du jeu, 1939), su cumbre estilística. Para Erich Von Stroheim el mundo ya mostraba por sí mismo la crueldad y no había razón para transformarlo. La mayor parte de la breve filmografía sufrió recortes: Esposas frívolas (Foolish Wives, 1921), Avaricia (Greed, 1923), La reina Kelly (Queen Kelly, 1928). 
al sarcasmo de Chabrol en Landrú (1962), pero estaban todos ellos lejos del realismo naturalista de Truffaut en Jules et Jim (1962), o la poesía discursiva de lo cotidiano de Rohmer en El signo del león (Le signe du lion, 1959); y distaban en su conjunto también del humor ascético de Bresson en Pick-Pocket (1959), o del existencialismo nihilista de Malle en Fuego fatuo (Le feu follet, 1962). Más allá de estas diferencias lo que unió a este complejo núcleo de cineastas, y de ahí su enorme potencial, fue la reivindicación del cine como lenguaje autónomo y el anteponer siempre la libertad creadora a toda exigencia comercial (Miguel Borrás, 2001).

\section{Hacia un replanteamiento de la esencia del cine}

Muchos cambios se han producido desde las renovaciones expresivas de los años sesenta. Los nuevos soportes han dado entrada a herramientas diferentes y esto está afectando a las formas y, por ende, al lenguaje. Parece que ha llegado el momento de replantear su esencia.

\subsection{La forma del film es su materia}

De la obra escrita por André Bazin -cuyo denodada defensa del Realismo provocó ciertas reticencias por parte de reputados críticos- se desprende un sólido corpus teórico cuyos postulados recobran significación en la actualidad. Esa forma de atender a la realidad como la única verdad posible en la representación, le llevó a realizar un profundo estudio sobre sus relaciones.

Dejando de lado su rechazo hacia el cine formalista (como vimos más arriba), fruto de ese interés hacia la naturaleza ontológica del cine, nos interesa rescatar algunas de sus reflexiones sobre las estrategias que articulan la representación.

Bazin, en contra de lo que pueda pensarse, también estaba interesado en entender cómo la historia condiciona el modo que tiene el artista de aprehender la realidad. Para el teórico francés, el cine es un organismo vivo que tiene que ir adaptándose al entorno dialogando con las artes y la historia. En A favor de un cine impuro, ensayo en el que desarrolla sus ideas sobre la ontología del cine, explica que por su naturaleza también se impregna de las pulsaciones de la cultura de la que forma parte, se trata de su ontogenia (1959, Op. cit.). En ese cruce entre ontología y ontogenia se encuentra el pensamiento baziniano. Mentor de la Nouvelle vague (fue el fundador de Cahiers du cinema) y rendido admirador del Neorrealismo, cuando la crítica italiana rechaza los films de Rossellini en los que se olvida de la realidad histórica, como una traición al movimiento, Bazin manifestó su oposición ${ }^{9}$ señalando que el postergar a un segundo plano el momento histórico no le separa del Neorrealismo, dado que "la forma del film no es un adorno del guión sino es su materia". Para Bazin el cine puede mostrar las formas de la realidad incluso despojada de cualquier artificio técnico; la

9 “Defensa de Rossellini”, carta abierta dirigida a Guido Aristarco (Ibíd: 381). 
materia prima de su lenguaje son los trazos que la realidad deja impresa en ellos. Una fotografía no reproduce la realidad (como ocurre al escuchar una melodía) sino que la transcribe. La cámara es un instrumento para capturar el mundo, huella mecánica, pero esa dependencia con la realidad no le convierte en garante de verdad.

\subsection{Una ética de la representación}

El cine realista, apunta Ángel Quintana, no busca un modelo que restituya la impresión de realidad, sino un discurso artístico que cree un diálogo entre las imágenes, el mundo y las relaciones que establece el hombre con las cosas. Una actitud ética ante la cultura del simulacro. El problema reside en la subjetividad de su existencia que contradice la objetividad de su esencia (2003, Op. cit).

Sugiere Quintana partir de una reformulación del Realismo genético para entender cómo se inscribe la realidad en la representación.

Revitalizar esas marcas de lo visible que fueron desplazadas por las artes... una ética de la representación, capaz de cuestionar los límites de lo virtual.... Un discurso epistemológico abierto al conocimiento del mundo, que habla de la relación de los individuos y las cosas y que se opone a su disolución en diferentes representaciones autosuficientes (Ibíd. 2003).

Un realismo, pues, entendido como actitud ética, más que estética. El cine es expresión de una determinada ideología, representa la realidad mediante una mirada, un encuadre, un punto de vista desde el cual acceder a los acontecimientos. La cámara, nos dice Marc Ferro (autor fundamental en las relaciones entre cine e historia) más que copia de la realidad, revela un secreto (1995).

El tema todavía no está cerrado quizá porque se debería salir de ese debate para asumir que el Realismo no es una cuestión estética ni de estilo, sino que es un problema de orden semántico, como señala Mario Brenta $(2012)^{10}$.

\subsection{Buscar la verdad de las cosas}

Es un hecho que el soporte técnico tan necesario para su consecución se está apoderando del cine.

La mirada de Rossellini, cuyo influjo fue determinante en estos cineastas rupturistas, su forma de entender el cine, despojado de cualquier artificio, constata la idea de que sólo con la sencillez, apartado del artificio de la producción, puede el director lograr la independencia y, con ella, reflejar la verdad de las cosas. Su punto de vista se deja sentir en la actualidad en cineastas como los hermanos Dardenne, Robert Guédiguian o Pablo Trapero y, por supuesto, Ipotesi Cinema, escuela con la que cerraremos estas páginas. Haciendo patente algo que señalaba Truffaut y con él la

10Entrevistas realizadas a Mario Brenta entre julio y noviembre de 2012, por la autora de este trabajo. Cineasta con el que cerramos nuestro estudio. 
Politique des auteurs ${ }^{1}$, en su reivindicación del cineasta como un autor total que debe implicarse en todo el proceso de creación; ideas a las que Jean-Luc Godard, añadía un aspecto interesante al señalar que era necesario cambiar el método de rodaje, acorde con el tema, más próximo a la realidad.

\subsubsection{Roberto Rossellini}

Es el cineasta que llevó hasta sus últimas consecuencias la estética Neorrealista. En Rossellini forma y contenido están absolutamente unidos; busca la verdad de su tiempo filmar las cosas como son, en su desnudez, no transformadas. En su cine no hay nada añadido, la realidad está despojada de todo aquello que no es imprescindible, sólo existe "puesta en escena de los hechos" (Bazin, Ibíd. Pág. 389).

Podemos pensar que esa desnudez expresiva, su rechazo hacia la dramaturgia clásica que desestabilizó las estructuras de Hollywood (importadas al cine Europeo), está provocada por las excepcionales circunstancias que se dieron en esos años. Roma citta apperta (1945) sería el ejemplo perfecto, ya que se trata de un film esbozado, desprovisto de todo efecto artístico. Esa Roma en ruinas ha pasado al imaginario colectivo, es parte de nuestra historia. El crítico Ángel Fernández Santos señalaba que Anna Magnani y Aldo Fabrizi, más que actores que fingen ser otros, son la propia Italia de 1944 reflejada en ellos. "Rossellini quiso contar una ficción y la verdad hizo de esta ficción un capítulo privilegiado de ella misma"2. Cine hermoso, conmovedor, que influyó de forma determinante en la producción europea posterior y, consecuentemente, también en Estados Unidos.

Sus films son un reflejo de una realidad que está en el exterior pero también en uno mismo. Una realidad heterogénea como sucedía en Paisa (1946), compuesto por episodios en los que el desembarco del ejército americano en Italia produce el cruce entre dos culturas. Fue un año después, con Germania anno zero, cuando la crítica le acusa de involución del Neorrealismo (como dijimos más arriba), pues se cuestiona el argumento sin dar cuenta del estilo que es precisamente el que le otorga el sentido. La experimentación en Rossellini viene impulsada más por la necesidad de sus temas -que requieren concepciones cinematográficas distintas- que por una voluntad de cambio. Las reglas de la dramaturgia clásica carecen de validez, sus films se ofrecen al espectador en holocausto, invitándole a la revelación de la verdad. (Bergala, 1984).

11 Los pensamientos esbozadas por Alexander Astruc en Caméra-stylo (del que hablamos más arriba) tuvieron difusión a través de la Cinemateque française y poco después en la revista Cahiers du cinema. Fundada por André Bazin en 1951. Ese año Truffaut publicaba en la revista el ensayo, Una cierta tendencia del cine y después Bazin La politique des auteurs (1957). Estas ideas tendrían su consecuencia en la Nouvelle vague.

12De Renoir a Rossellini crítica publicada en El País el 10 de enero de 1985 (En la sección "El cine en la pequeña pantalla"). A propósito del inicio de un ciclo dedicado a Rossellini en la Segunda Cadena de TVE. 


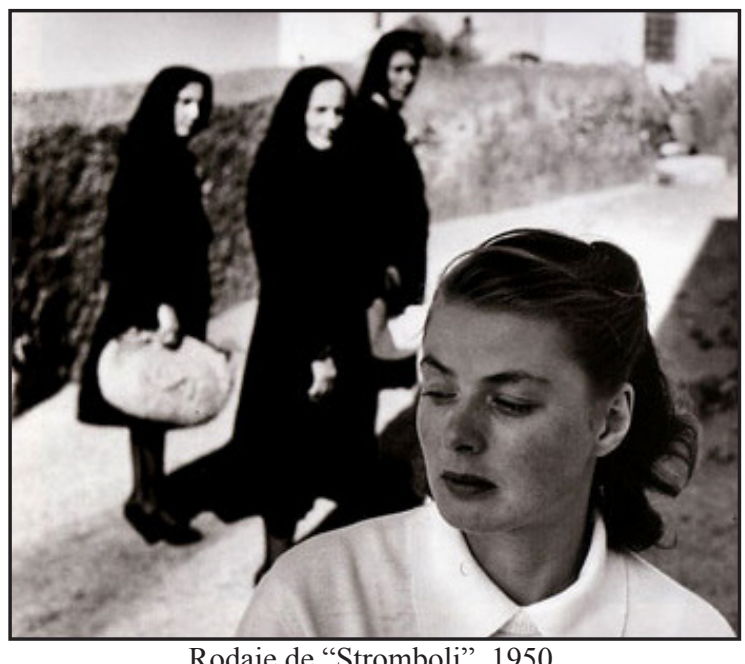

Rodaje de "Stromboli", 1950.

El encuentro del cineasta con Ingrid Bergman hace posible su idea de que una película es el documento de su propio rodaje. En Stromboli (primer film que realizan juntos), la llegada de Bergman, por entonces una estrella de Hollywood, a una pequeña isla en la Italia de la posguerra, provoca el escándalo que, por ende, es el tema del film (también su matrimonio fue objeto de controversia). En Europa 51 (1952), el comportamiento de la protagonista experimenta un giro radical tras la trágica muerte de su hijo y remueve su conciencia. Sus nuevos valores cuestionan la ideología de la sociedad burguesa a la que pertenece.

Pues ese alejamiento de la realidad de su tiempo que le reprocharan sus colegas neorrealistas, para Rossellini suponía desvelar la capacidad del cine para mostrar lo grande a través de lo pequeño; captar mejor la verdad que abarcando los grandes problemas de la época.

\section{Ipotesi Cinema}

Creada en 1982 por Ermanno Olmi y Paolo Valmarana (crítico y responsable de programación de RAI 1), en Bassano del Grappa, esta escuela de cine nace con el propósito de abrir nuevas vías de expresión a la creación cinematográfica. Basa sus principios en provocar el acercamiento del lenguaje del cine hacia la realidad, alejado de todo artificio, libre de condicionamientos industriales (condición sine qua non) y dando como resultado films realistas concebidos desde un punto de vista muy cercano al documental y al mismo tiempo a la poesía.

Hablar de Ipotesi supone mencionar a Ermanno Olmi, su principal artífice, que lleva más de 50 años (Il tempo si è fermato, 1958) indagando en los problemas del 
hombre enfrentado al desafío que supone vivir. Desde sus primeros films, impregnados del Neorrealismo, su mirada se ha ido acercando cada vez más a un realismo poético (El árbol de los zuecos; L'albero degli zoccoli, 1978), que le conduciría, en la década de los 80, a un cine integrado en la metáfora (La leyenda del santo bebedor; La leggenda del santo bevitore, 1988).

También el cineasta Mario Brenta es fundamental para entender los principios esencialistas de esta escuela. Como Olmi, Brenta se va distanciando del nexo narrativo que unía a los films de su primera etapa (Vermisat, 1975; Maicol, 1989) -retratos de marginación provocada por el sistema- inmersos en un realismo fenomenológico, para profundizar en una subjetividad dispersa con estructuras más libres cercanas a la poesía (Calle de la Pietà, 2010, y Agnus Dei, 2012, codirigidas ambas con Karine de Villers) penetrando en una visión simbólica de la realidad, creada con una lógica más emocional que racional.

Aunque los planteamientos realistas de ambos cineastas hayan cambiado (se distancian de esa semejanza con el referente), sus films siguen impregnados de esa poética de la que hablamos que se produce en el encuentro entre el lenguaje y la realidad abriéndose hacia la pluralidad de sentidos.

\subsection{Principios para una scuola-non scuola}

Ipotesi Cinema está integrado por un grupo heterogéneo en edad, experiencia e ideas, pero unido por el inconformismo que investiga en el lenguaje buscando la esencia del cine, o de la realidad, que para estos cineastas forma parte de la misma idea.

Se trata de una escuela (non scuola, como la denominan sus miembros) en la que se da prioridad al uso automático e irreflexivo del lenguaje como descubrimiento. La fase teórica se plantea como aspecto reflexivo a partir de la experiencia y conocimiento adquiridos en la relación directa con la realidad. Paradójicamente basa su trabajo en la investigación y estudio del lenguaje cinematográfico y fundamenta sus estudios y discusiones teóricas poniendo en funcionamiento las ideas expuestas a partir de la Gran sintagmática de Metz, la semiología y consecuentemente los estudios postestructuralistas que abordaron el film como texto, ese lugar donde el lenguaje se trabaja (González Requena, 1983), donde confluyen múltiples significantes, una galaxia de sentidos abierta a la pluralidad, como señalaba Roland Barthes (1973).

Se aprende a mirar y esto lleva implícito la expresividad y la emoción, vehículos inseparables de la comunicación y el arte. Se trata de encontrar el vínculo que une contenido-forma como parte de un mismo corpus. En este proceso se deja sentir, e irrumpe, la voz del artista.

El registro de esa mirada surge de nuestra memoria, resultado de la percepción y la reflexión. "La memoria es un acto natural -perceptivo- y creativo, produce el relato de nuestra vida. Lo que nuestra conciencia recoge de la existencia a través de la percepción y la participación". (Brenta. Ibíd, 2012) 
Mario Bisatti, exalumno y profesor de la escuela, manifiesta que la esencia de esta experiencia radica en que el estudiante encuentre su propia voz para representar "eso que busca". Provocar ese encuentro con la realidad supone una escucha atenta. Experimentar en el lenguaje de la vida, su naturaleza simbólica. La vida en su acontecer cotidiano es la mejor escuela de dirección que existe (Bisatti, 1992: 5).

Para lograrlo propone Olmi detenerse y esperar el acontecer.

La contemplación es la confianza en un asombro que seguramente se producirá, si dispones de tiempo y corazón para esperar. Es lo que yo denomino, un emplazamiento ("postazione") para la memoria" (Olmi, 1992: 2).

\subsubsection{Osolemio: autoritratto italiano}

Resultado de estas experiencias, amén de films estrenados comercialmente ${ }^{3}$, durante estos años se realizaron tres obras colectivas -Di paesi, di città; Il Serpentone; Osolemio: Autoritratto italiano- elaboradas mediante una estructura caleidoscópica que aborda la realidad desde miradas (voces) diferentes, y constatan la solvencia de los planteamientos metodológicos de Ipotesi Cinema.

Osolemio: Autoritratto italiano (presentada en la Mostra de Venecia, 2004) se plantea como una reflexión sobre los aspectos gramaticales del lenguaje cinematográfico que inciden directamente sobre su retórica como vehículo para la expresión artística. Partiendo de un tema general - plasmar lo que sucede en la Italia actual-, trabajaron sin ninguna imposición en una realidad de la que sus creadores participan como observadores y actores. Esa observación atenta de la realidad ("postazione") es la que dio lugar a las ideas (son las cosas las que llevan a los conceptos y no viceversa). Lo que aparece en la superficie es fundamental para llegar a entender los múltiples sentidos que oculta en su interior.

Cada uno de los veintiocho artistas que participaron en el film efectuó su propia "postazione" y así se lograron esbozos diversos a partir de los que se fue reconstruyendo la película. Osolemio: Autoritratto italiano funciona como un hipertexto en el que cada estudiante-autor se reencuentra con su propia historia. Una suerte de introspección de la mirada, espejo fragmentado que refleja una única luz pero en la que se percibe la intermitencia constante creada por el flujo de puntos de vista. Un conjunto de realidades, una suerte de microrrelatos, que se enlazan formando un puzzle de afinidades y contrastes que en su conjunción devuelven la idea de Italia.

13 La terra (Luciano Zaccaria, Toni de Gregorio, Rodolfo Bisatti, 1988); Maicol (Mario Brenta, 1988); In coda alla coda (Maurizzio Zaccaro, 1989), L'attesa (Fabrizio Borelli, 1991; Quasi un anno (Giorgio Diritti, 1996) Domani (Giulio Ciarambino , 1997), Tre storie ( Piergiorgio Gay e Roberto Sanpietro, 1998), Case (Rodolfo Bisatti, 1998), son algunos ejemplos. 


\section{Coda Conclusiva: la esencia del cine según Mario Brenta}

La revisión de las formas expresivas del cine efectuadas a lo largo de estas páginas nos ha conducido hasta Mario Brenta. El corpus teórico articulado en L'Occhio Selvaggio $(2011)^{4}$, fruto de su experiencia como profesor y cineasta, conforma un gran texto en el que se percibe un mismo deseo por acercarse a la realidad a través del lenguaje en busca de su esencia, y responde a las cuestiones planteadas al iniciar este trabajo.

El lenguaje audiovisual, señala Brenta, es innato en el hombre, dada su necesidad de interpretar la realidad con la que se va encontrando. Independiente, pues, del lenguaje escrito y relacionado con las infinitas posibilidades que ofrece la imagen mental. El cine no tiene que dar respuestas, sino sugerir cuestiones que provoquen al espectador.

Brenta huye de la mirada objetiva y propone una distancia con la verosimilitud del significante. "Metáfora de la realidad, pero realidad" (Op. cit., 2012). Es posible que exista una amplia distancia entre el referente y el significante o es posible que coincidan. El realismo no puede reducirse a un problema de verosimilitud. Lo verosímil no siempre es verdad. Se trata de buscar en la expresión nuestro modo de ver el mundo.

En el lenguaje audiovisual la interpretación conceptual parte de una realidad primitiva, virgen, rica en significados por descubrir. Se trata de filmar el pensamiento a través de las cosas y no viceversa. Tras esta intención redentora de sus palabras se perciben ecos esencialistas de Kracauer y Bazin.

"El lenguaje -afirma el teórico italiano- se encuentra en ese momento en que se pasa de lo puramente perceptivo a lo expresivo. Nuestro 'ser en el mundo' con el que nos relacionamos a través de un proceso de simbolización-abstracción" (Ibíd, 2011: 4). Esto nos conduce hacia una idea que se encuentra en el epicentro de esa esencia del cine de la que venimos hablando: "El cine es una suerte de protolenguaje universal que el hombre ha adoptado desde siempre... La capacidad de contar-concluye el cineasta- no nace de saber explicar sino de saber vivir" (Ibíd: 27).

\section{Bibliografía}

Libros

ARISTARCO, G. (1960): Storia delle teoriche del film (Nuova edizione riveduta e ammplita). Giulio Einaudi Editore.

AUERBACH, E. (1975): Mimesis: La representación de la realidad en la literatura. México: Fondo de Cultura Económica.

BARTHES, R. [1973] (1980): El placer del texto. Madrid: Siglo XXI Editores.

14L'Occhio Selvaggio es un libro inédito, escrito por Mario Brenta y concluido a finales de 2011. 
BAZIN, A. [1959-62] (1990): ¿Qué es el cine? Madrid: Ediciones Rialp.

BERGALA, A. [1984] (2000): Roberto Rossellini. El cine revelado. Barcelona: Paidós

BRUNETTA, G. P. (2008): Il cinema neorealista italiano. Da Roma città aperta a I soliti ignoti. Roma: Laterza.

FERRO, M. (1995): Historia contemporánea y cine. Barcelona: Ariel.

GOMBRICH, E. [1960] (2003): Arte e ilusión. Madrid: Debate.

GUBERN, R. (1996): Del bisonte a la realidad virtual. Barcelona: Anagrama.

JAKOBSON, R. [1963] (1985): Ensayos de lingüística general. Barcelona: Planeta Agostini.

KRAKAUER, S. [1960] (1989): Teoría del cine. La redención de la realidad física. Barcelona: Paidós.

LUKÁCS, Georg (1977): La novela histórica. México: Era

METZ, C. [1968] (2002): Ensayos sobre la significación en el cine (1964-68). Vol. 1. Barcelona: Paidós

MIGUEL BORRAS, M. (2001): Historia del cine con cien películas. Vol. 11 y 12. Madrid: Acento Editorial.

MUGUIRO, C. (ed.) (2008): Ermanno Olmi. Seis encuentros y otros instantes. Gobierno de Navarra.

QUINTANA, Á. (2003): Fábulas de lo visible. El cine como creador de realidades. Barcelona: Acantilado

(2011): Después del cine. Imagen y realidad en la era digital. Barcelona: Acantilado.

TRUFFAUT, F. [1951] (1987): El placer de la mirada. Barcelona: Paidós

ZUNZUNEGUI, S. (1998). Paisajes de la forma. Madrid: Cátedra, Signo e Imagen.

Capítulos o artículos en libros o revistas en papel

ERICE, V. (1997): Víctor Erice. En. Revista Banda Aparte. $\mathrm{n}^{\circ} 9$ y 10. Valencia.

GONZALEZ REQUENA, J. (1983): Para una definición de una teoría del texto artístico". En M. GARRIDO (ed.) Teoría, Semiótica y lenguajes hispánicos. Madrid: CSIC

MIGUEL BORRAS, M. (2008) La Poética del cine. En: Miguel, Borrás, M.; Bermejo Berros, J.; Canga Sosa, M.. Siete miradas, una misma luz (Teoría y análisis cinematográfico). Valladolid: Servicio Publicaciones Universidad de Valladolid.

OLMI, E. (1992): A propósito di una scuola non scuola di cinema. (Dichiarazione dattiloscritta di Ermanno Olmi, dal fascicolo A proposito di una non-scuola di cinema).

VV. AA. Materiali di Ipotesi Cinema in dieci anni della sua storia, Bassano, 1992, conservato presso il Fondo Paolo Valmarana, Cineteca di Bologna. 
Artículos en publicaciones web

BOKSER, Julián (2011). Lukács, Bretch y Adorno: Un recorrido posible. La revista del CCC [en línea]. 2011, $\mathrm{n}^{\circ}$ 12. http://www.centrocultural.coop/revista/articulo/250/. Consultado el 9-9-2013.

ESQUEDA VERANO, Lourdes.; CUEVAS ALVAREZ, Efrén (2012). Entre la huella y el índice: relecturas contemporáneas de André Bazin. Revista Área Abierta ${ }^{\circ}$ 33. http://dx.doi.org/10.5209/rev_ARAB.2012.v33.4055. Consultado el 12-92013

\section{La autora}

Mercedes Miguel Borrás, Profesora Contratada Doctora (Universidad de Valladolid) imparte asignaturas sobre Lenguaje audiovisual; Guión; Realización de documentales (Grado Periodismo); Principales Teorías cinematográficas (Máster). Ha publicado, entre otras obras, las siguientes: La representación de la mirada: "La ventana indiscreta (A. Hitchcock, 1954). Ed. de la Mirada, 1998; La letra en el cine: escritores en el cine europeo (Coord.) Centro Doc. Europea, 2005; Siete miradas, una misma luz (Teoría y análisis cinematográfico). (Coord.) Servicio Publicaciones, Universidad Valladolid, 2008; Imaginarios del franquismo: La prima Angélica y El Espíritu de la colmena. Orillas. Rivista D'Ispanistica. Universidad degli Studi di Padova, 2013. Es investigadora Principal: "Comunicación Icónica: Imágenes de la Historia Contemporánea” (Subvencionado Junta Castilla y León; 2005-08). 